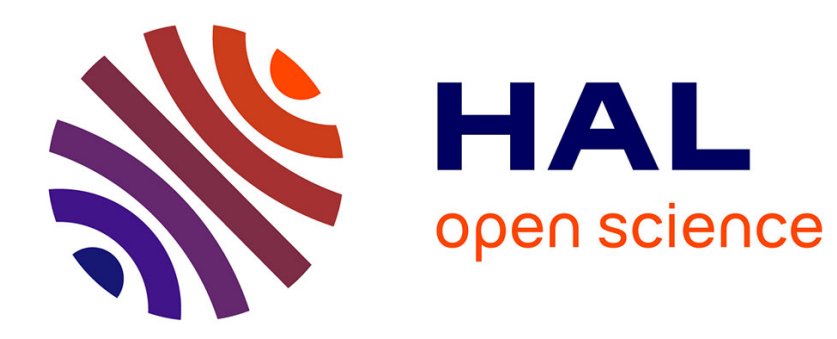

\title{
Applications of Shape Memory Effects
}

P. Besselink, R. Sachdeva

\section{- To cite this version:}

P. Besselink, R. Sachdeva. Applications of Shape Memory Effects. Journal de Physique IV Proceedings, 1995, 05 (C8), pp.C8-111-C8-116. 10.1051/jp4:1995812 . jpa-00254060

\section{HAL Id: jpa-00254060 https://hal.science/jpa-00254060}

Submitted on 1 Jan 1995

HAL is a multi-disciplinary open access archive for the deposit and dissemination of scientific research documents, whether they are published or not. The documents may come from teaching and research institutions in France or abroad, or from public or private research centers.
L'archive ouverte pluridisciplinaire HAL, est destinée au dépôt et à la diffusion de documents scientifiques de niveau recherche, publiés ou non, émanant des établissements d'enseignement et de recherche français ou étrangers, des laboratoires publics ou privés. 


\title{
Applications of Shape Memory Effects
}

\author{
P.A. Besselink*,** and R.C.L. Sachdeva** \\ * Memory Metal Holland, Gronausestraat 1220, 7534 AT Enschede, The Netherlands \\ ** Memory Medical Systems, 2605 Courtside Lane, Plano, Texas 75093, U.S.A.
}

\begin{abstract}
.
In this paper a series of new medical applications for specific behaviour of shape memory alloys is presented.

Several properties are well known, like the superelasticity and the shape memory effect, but there are some other interesting features that are used very scarcely.

Examples are given of the use of the extraordinary shapeability of the martensitic material, in some cases in combination with high tensile strength, which makes memory metal a very special engineering material.

For applications of superelasticity a new alloy was found, that exhibiths improved stiffness and an upper platean stress as high as $1000 \mathrm{MPa}$.

Single crystals show perfect constant plateau stresses, which give a well defined force in medical tools.

Examples are given of instruments and medical implants using memory metals for functions as distraction, adjustability for customization, measuring, steerability and locking/unlocking of devices.
\end{abstract}

\section{SMARTINI-ORTHODONTIC RETAINER WIRE}

SMARTINI stands for Smart MARtensitic TINI-wire which can be used to stabilize the dentition after active orthodontic treatment.

The material property that is used here is the extremely easy ( up to $7 \%$ strain ) deformation in the martensitic state. Only about $200 \mathrm{MPa}$ is required to reach this $7 \%$ strain.

Therefore it becomes very easy to bend the wire to the lingual surfaces of dentition accurately. This not only adds to the speed of the operation but also results in more reliable bonding of the retainer, because of its superior adaptation to the dentition. This is combined with the relatively high stiffness and tensile strength when the material is deformed above this $7 \%$ strain. The maximum stress is higher than $1200 \mathrm{MPa}$.

Memory metal combines two properties which appear to be possible only for two different metals: it is extremely deformable and very strong.

\section{DISTRACTION OSTEOGENESIS DEVICE}

Distraction osteogenesis is a well established therapeutic approach, used to lengthen bones. This is accomplished by slicing the bone into two fragments and applying forces between these parts after a latency period of 7-10 days. Bone is distracted at the rate of $1 \mathrm{~mm}$ per day. Present devices are cumbersome and do not allow for precise activation. Therefore a shape memory based device has been designed to overcome these difficulties.

A memory metal wire is used in combination with a double ratcheting device to work as a remote controlled step-motor for the distraction of bone or soft tissue. The memory metal wire acts against a biasing spring, which resets the wire after a heating cycle. During contraction by electrical heat the wire 
moves a ratcheting pawl to a next position along a toothed rack. When the wire cools down below the transformation temperature range, it becomes soft and the bias spring strains the wire again. At this moment the second pawl on the other end of the wire moves along the same toothed rack.

After one complete temperature cycle the system has moved (like a crawling caterpillar) one distinct step along the rack, and this procedure can be repeated as often as desired.

This apparatus can be used as an implantable device for all kinds of Ilizarov distraction techniques, where corrections have to be made with a predictable shape change at distinct moments, with high forces and within a very small area. Activation can be achieved by direct resistance heating of the memory metal wire.

Other possible applications of this device include:

- lengthening of a growing prosthesis.

- correction operations in e.g. the maxillofacial field.

- distraction of long bones to overcome bone length differences.

- distraction of soft tissues like tendons.

- industrial applications.

The prototype that has been shown in fig. 1 works with a $40 \mathrm{~mm}$ long NiTi-tension wire with a diameter of $1.1 \mathrm{~mm}$, working in a cylindrical housing of $7 \mathrm{~mm}$ outer diameter and a length of $57 \mathrm{~mm}$.

Per temperature cycle this motor makes a longitudinal step of $0.8 \mathrm{~mm}$ against a load of maximal $400 \mathrm{~N}$.

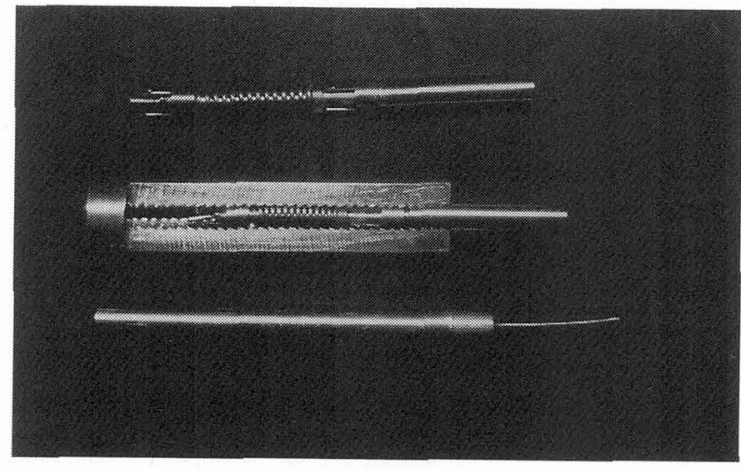

Figure 1a: Distraction device, showing the interior parts (above) assembled in an open model (middle) and in the $7 \mathrm{~mm}$ diameter housing (lower).

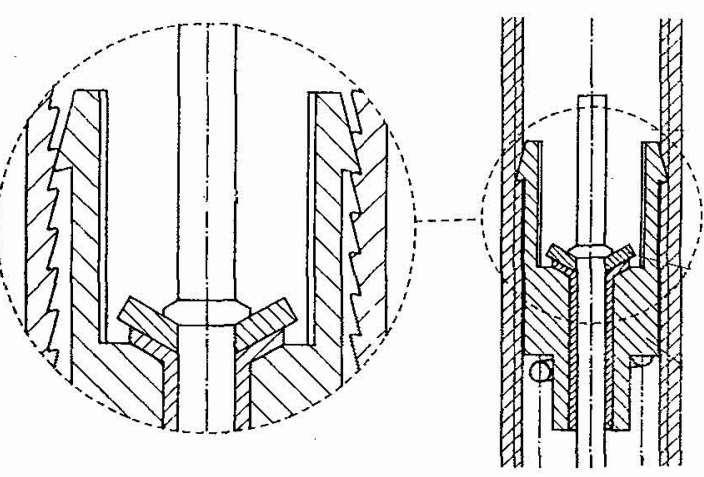

Figure 1b: Construction of the distraction device. (Detail).

\section{STEERABLE INSTRUMENTS USING SUPERELASTICITY}

A wide range of steerable catheters, guidewires and other medical instruments has been developed recently by several companies $[1,2,3]$ and some of them are using superelasticity in a very effective way.

Like the Homer Mammalok [1] needle, the curved tip of a superelastic wire or tube is pushed out of a straight delivery tube over an adjustable length. This causes a predictable deviation of the tip from the central axis of the instrument. Rotation around this axis in combination with relative axial displacement gives a good steerability. The next generation of instruments according to this principle uses a superelastic capillary tube [4] with curved tip, holding optical fibers and a lens at the distal end. In this way a miniature steerable 
endoscope or laser cutter can be made with a diameter of less than $1 \mathrm{~mm}$.

The same principle can be used for steerable knifes, chisels, suction tubes and grippers for minimal invasive surgery. These tools are either made of superelastic material with a curved shape, or mounted on top of a curved superelastic shaft. See fig. 2, showing the knife in the delivery tube (left) and pushed out (right).

For these instruments the use of superelastic NiTiNb instead of conventional superelastic NiTi brings the advantage of a higher E-modulus (65 as compared to 40-50 GPa at body temperature) and a higher loading plateau stress (900-1000 MPa as compared to 400-500 MPa at body temperature)[5].
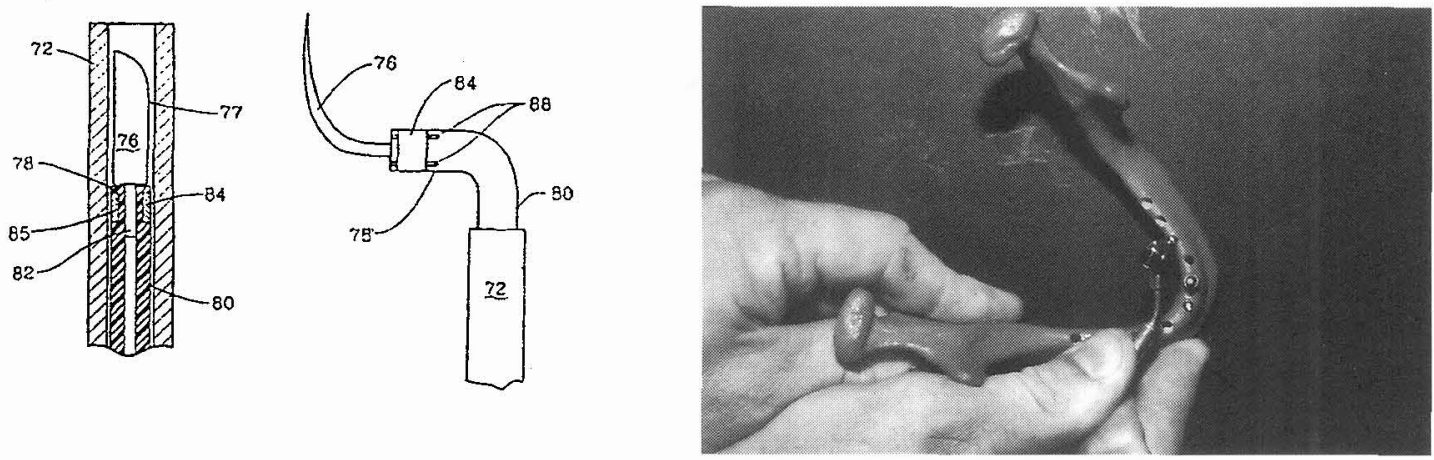

Figure 2: Steerable knife, using superelasticity. Either knife 76 or rod 80 has been programmed into a curved shape.

Figure 3: Superelastic torque wrench, indicating the optimum torque between 30 and $35 \mathrm{Ncm}$.

\section{SUPERELASTIC TORQUE WRENCH}

When small parts like a dental abutment have to be mounted securely on a dental root implant with a fine thread, it is very important to apply a correct torque. If the torque is too low the connection is not stable enough and if it is too high the thread can be damaged or the connection between the surrounding bone structure and root implant looses its stability.

To overcome these problems a very compact and reliable superelastic torque wrench was developed.

A part of the stem is made of a superelastic wire made of CuZnAl-single crystal with a well defined loading plateau stress.

The abutment is screwed onto the root implant by hand until it is almost tight and then the torque wrench is put into a side hole to apply the desired final moment. The dentist can raise the torque until he feels and sees the onset of severe bending of the superelastic wire, indicating that the critical torque has been reached. (See fig. 3)

This tool has originally been developed for use in the dental area, but the same principle can be implemented into industry as well. 

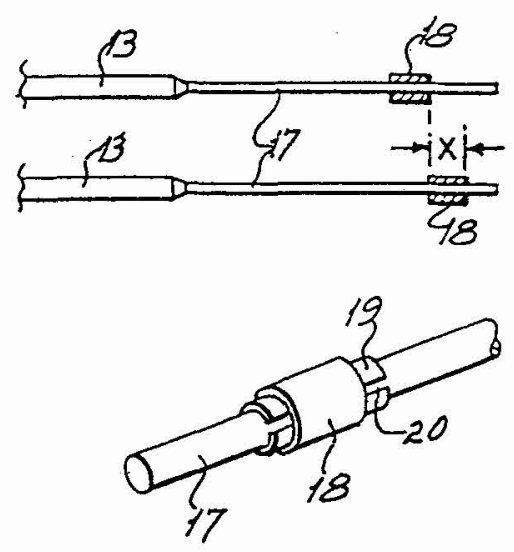

Figure 4: Sliding stop on a facebow, working with a biasing sleeve.

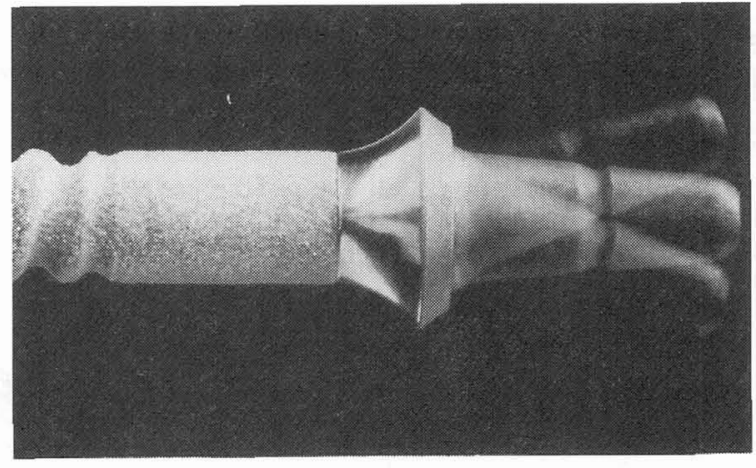

Figure 5: Dyna adjustable dental abutment, shown in 3 positions.

\section{ASSEMBLY OF MODULAR DEVICES}

The use of modular medical or dental devices, instruments and implants brings several advantages like easier sterilization, more flexibility, customization, adjustability etc.

For example the use of a universal handpiece in combination with a set of tools connected thereto can strongly reduce cost. Memory metal elements can be used for locking distinct parts of the modular device together in any desired configuration to get a stable, yet adjustable assembly. This can be achieved in several ways :

\subsection{SLIDING STOP}

In several medical techniques the use of an adjustable stop on a long cylindrical pin brings advantages. In face bows, lip bumpers and Herbst appliances for orthodontic treatment these stops are used to adjust the displacement of the teeth or molars.

Conventional stops are clamped with side screws or crimped, the latter being definitive and not readjustable.

With a memory metal ring, eventually combined with a biasing sleeve it is possible to slide the stop over the pin after cooling. The same principle can also be used to put a drill stop on a Kirschner nail, used for fixation of bone parts. The stop can also work as the head of a nail with adjustable length, where the excessive part of the nail can be cut off. (See fig. 4)

\subsection{LOCKABLE BALL JOINT}

In dental implants the need for adjustability of the position of the teeth is obvious. Dyna [6] developed a system with a root implant that is inserted into the bone and after healing, an abutment is screwed on top of this implant. The lower part of the abutment is a spherical cup and the upper part is a memory metal stem with a slotted ball that fits in the cup. The memory metal ball has been programmed to a diameter that is about $3 \%$ larger than the inner diameter of the cup. After insertion at low temperature the combination ballcup warms up to normal temperatures and the memory metal ball is locking itself, holding the stem in the desired position.

Finally the dentist puts a crown over the stem. Readjustment can be achieved by cooling and the recovery force completely disappears. (See fig. 5) 


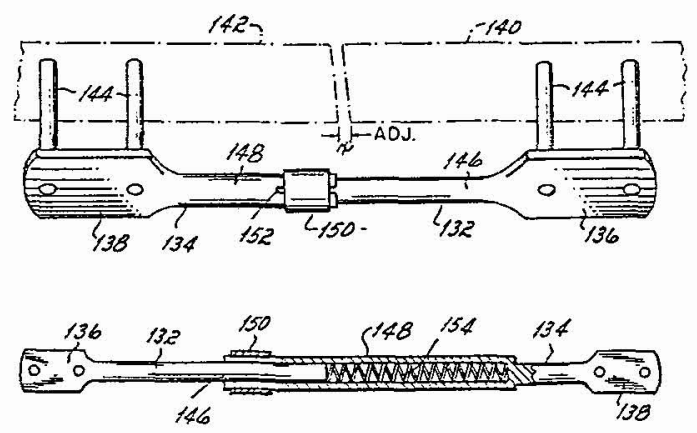

Figure 6: Telescopic adjustable orthopaedic internal fixator, locked with a Memory Metal ring, eventually preloaded with a spring (below).

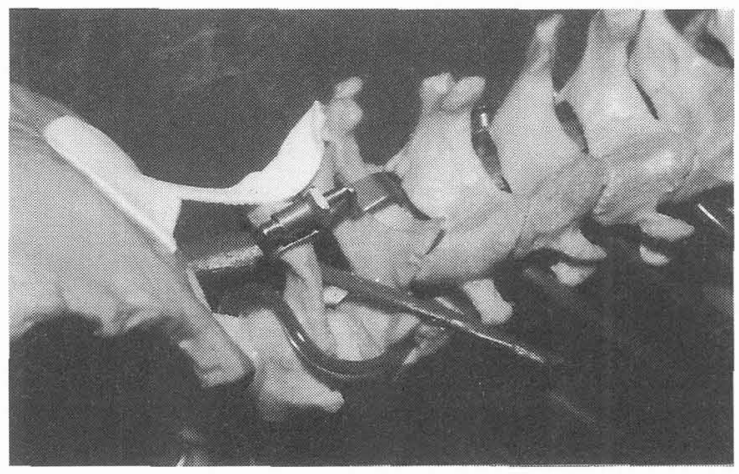

Figure 7: Adjustable interlaminar clamp for cervical fixation in the spine.

\subsection{CYLINDRICAL LOCKING RINGS}

Cylindrical locking rings [7] are used to lock telescopically engaging parts of orthodontic face-bows, orthopaedic external and internal fixators, adjustable instruments and all kinds of adjustable clamps for spinal fixations. (See fig. 6 and 7).

The hysteresis in the transformation makes it possible that the memory metal is in the adjustable configuration or that the strength of the fixation has the desired value, both at body temperature. In that case the transformation to austenite should lie slightly above body temperature. An alternative is the use of a memory metal with much lower transformation temperature in combination with a coolant.

Cylindrical locking rings in bone plates can be used to clamp the head of bone scews after they have been inserted into bone. This prevents the rotation of the stem of the bone screw, preventing unscrewing during use.

\subsection{LOCKING DEVICE FOR CERCLAGE WIRE}

In complicated operations like spinal corrections the use of cerclage wires or ligatures is very common.

These wires are tied around bone parts and then twisted together to close the loop. The free ends are cut off but there is always a remaining part that might cause irritation to the soft tissues and sometimes the wires do not hold because they can twist back.

The locking device with a piece of memory metal strip [7] replaces the twisting method. Below thetrans formation temperature the free end of the cerclage wire can move freely back and forth, but as soon as the memory metal is activated it locks the wire securely in place, preventing any further movement. Figure 8 shows the cerclage wire, the mounting bracket and the locking strip.

The free end can be cut off evenly and a smooth surface is the result. 

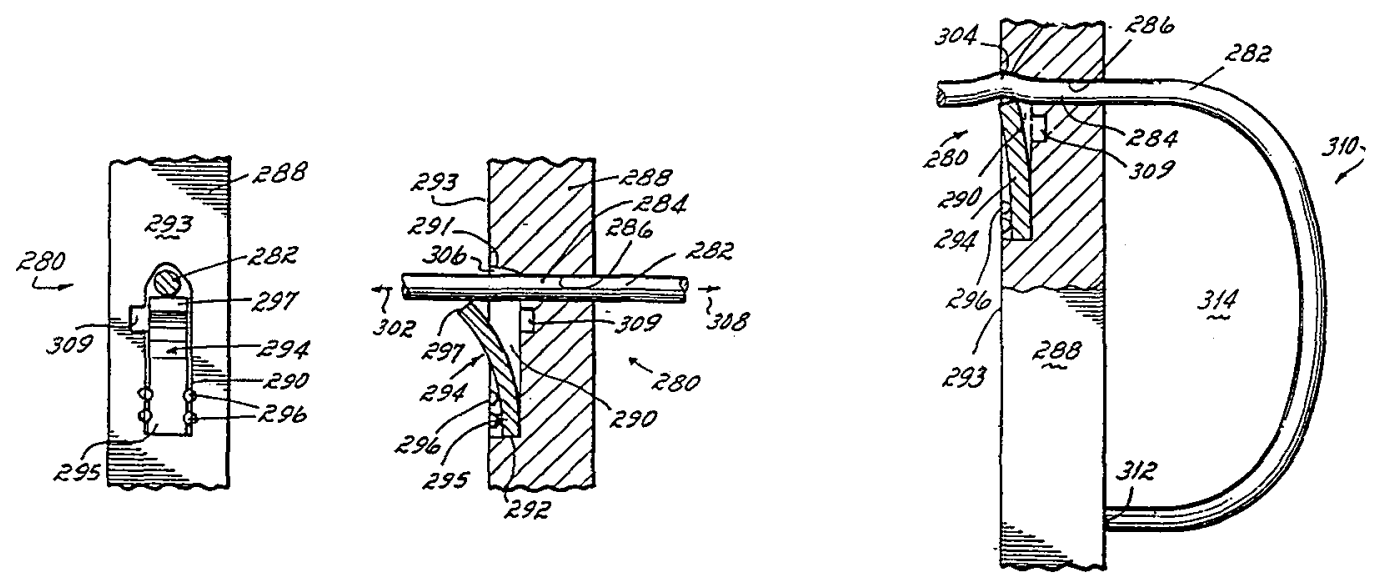

Figure 8: Locking mechanism for cerclage wire 282. Memory element 294 remembers its straight shape when heated.

The use of memory metal locking elements also brings the advantage that no extra tools are needed to attach the parts together with bolts and nuts. In conventional devices the external forces, applied on these tools, cause reaction forces on the bone and the soft tissues. This is not the case with memory metal elements that only need a defined temperature trigger, and the quality of the connection is not dependant anymore on the craftmanship of the surgeon. In contrary, it is defined by the tolerances that the manufacturer can control, so the risk of undesired sudden movements can be reduced, provided that the surgeon works with the prescribed temperatures.

\section{CONCLUSION}

As a result of their unique thermomechanical characteristics and biocompatibility shape memory alloys offer the medical community the ability to design more efficient and compact medical devices.

The future holds great promise for the application of these alloys.

\section{REFERENCES}

[1] J.P.O'Leary,J.Nicholson,R.Gatturna,in T.Duerig et al (Eds.),Engineering Aspects of Shape Memory Alloys,Butterworth and Heinemann, (1990) p. 477.

[2] S.S.Moran, "Flexible Instruments in Minimal Invasive Surgery", proceedings SMST, ASILOMAR March 7-10, (1994) pp. 411-416.

[3] P.P.Poncet and R.Zadno, "Applications of superelastic Ni-Ti in laparoscopy", proc. SMST, Asilomar March 7-10, (1994) pp. 421-426.

[4] R.C.L.Sachdeva and P.A.Besselink, "Instrument for endoscopic-type procedures", patent pending.

[5] P.A.Besselink and R.C.L.Sachdeva, "NiTiNb processing method and articles formed from the alloy", patent pending.

[6] Dyna Dental Engineering, (company brochure) Bergen op Zoom, The Netherlands.

[7] P.A.Besselink and R.C.L.Sachdeva, "Temperature Sensitive Medical/Dental Apparatus", patent pending. 